\title{
NEW SPIRITUAL ADVENTURES IN THE MISSION FIELD
}

\author{
By J. H. OLDHAM

\section{The National Christran Councils-their SignificANCE}

The National Christian Conference held in Shanghai last May, attended by about 1000 delegates appointed by the churches and missions throughout China, created a National Christian Council of $\mathbf{1 0 0}$ members to take the place of the China Continuation Committee, and this Council, when formed, decided that to discharge its responsibilities it needed a group of whole-time officers. A week or two later a National Christian Conference in Japan appointed a committee to approach the churches and missions in Japan, and invite them to co-operate in constituting a National Christian Council for Japan. Earlier in the year, following upon discussions in the Representative Councils of Missions in the different provinces of India, the National Missionary Council in that country resolved to transform itself into a National Christian Council, and, if the necessary funds were forthcoming, to appoint a group of five officers to serve the Christian forces in India, and in particular to assist in the solution of the problems of village education.

The cost of these proposals if carried into effect will be considerable, and there are difficult practical questions to be faced in determining the best method of financing them, and in obtaining the necessary funds. The fundamental question, however, is whether the plans themselves are sound, and whether they are likely to yield valuable results.

The significance of the new proposals will in my judg- 
ment be largely missed if we think of them primarily as a fresh step in organization. An increase of machinery is one of the last things needed in the mission field. As I understand the proposals they are a call to spiritual adventure. They will succeed or fail in the region of the spirit. It is necessary for their success that there should be a common mind as to what we are trying to do. This paper is submitted as a contribution towards reaching that common mind. It represents only the conclusions at which I have myself arrived and not the considered views of any of the National Christian Councils or of the International Missionary Council.

In the title of this paper the plans proposed are described as new spiritual adventures. They are of course not new in the sense that experiment is being made for the first time. Considerable results in missionary cooperation have already been achieved, both in the mission field and at home. But while the new proposals have been drawn up in the light of experience already gained, they mark fresh beginnings in each of the countries concerned, and the discussions in regard to them have helped to set in a clearer light the problems involved in missionary co-operation. It is only gradually that the significance of what was done at the World Missionary Conference at Edinburgh in 1910 is becoming apparent. At that Conference for the first time the conviction that it is necessary for the Christian forces to think together and do things together became sufficiently strong to lead to the appointment of a committee with a budget and whole-time officers to make this possible. The idea of independent missionary bodies contributing proportionately to a common budget in order to do certain things in common is thus a quite recent development. The action taken this year in India, China and Japan is an attempt to give further effect to this idea. It thus raises in a new and more acute form the issues involved and compels us to think out afresh what we want to do and how it ought to be done. The problem 
that confronts us is the problem raised by the World Missionary Conference, but the experience of the past few years both in the mission field and at home, and in particular the conferences and discussions of last year, have helped to clarify the issues. We have, as it were, climbed several steps higher on a spiral stairway and gained a new vantage ground and wider vision.

\section{Natronal Christian Councils-Problems to be Solved}

One of the outstanding facts about the missionary movement, which might well startle and perturb us if we had not grown so accustomed to it, is that the planning and direction of the Christian movement in great countries like China and India is in the hands of some hundreds of separate agencies-different missions, churches which have been established through their efforts, and the boards and societies in western countries which ultimately control the policy of the missions. This state of things is a serious weakness.

There may be comparatively little territorial overlapping, but it is inevitable that under this system work should develop out of balance. Certain grades of education will be disproportionately developed, while others will be neglected. Special types of work, such as the production of Christian literature, will tend to receive insufficient attention, because no single agency can do what is needed in the interest of the work in the whole area. Defects of this nature can hardly be avoided so long as policies are planned separately and independently, and decisions have to be made when the other parties whose views and intentions might influence them, or be influenced by them, are not present.

No great campaign could succeed if the planning of operations were left to the individual judgment of platoon commanders or even of brigadiers. Nor could it safely be 
left, as the late war showed, to allied governments with their general staffs acting independently of one another. It was essential to success in the war that the campaign should be viewed as a whole. Though this is the best illustration I can think of to enforce the point which I wish to make, I have hesitated to use it because some people are likely to say, "That is precisely the ground of our objection to these new plans. What is proposed is in effect the creation of a general staff for Christian missions, and that is just what we do not want. We are not prepared to surrender our judgment to any general staff, and we do not believe that any group of men can be found to take an impartial, unpartisan, comprehensive and balanced view of the missionary enterprise as a whole which will entitle them to direct missionary policy.' But is it not possible to distinguish between the authority possessed by a general staff, and their function as providing a view of the campaign as a whole? It is only when we make this distinction that our real problem emerges. It will be shown in a moment that the peculiar and distinctive character of the proposed National Christian Councils is that they are bodies which have no authority and no power to take decisions. That power lies elsewhere. But is not a view of the whole as essential to the success of the missionary enterprise as to the successful conduct of a military campaign? If it is, we have done nothing to solve our problem when we have said that we will not have a general staff. Just because we have rejected the idea of a general staff we are left with the question whether it is possible by any other means to provide for that view of the whole which is essential to the success of the work in which we are engaged. It is not suggested that nothing has been done towards gaining this view of the whole. But on any serious view of the problem, what has been done thus far is quite inadequate. It is imperative that something more be done. If the plans for the National Christian Councils are not the best way of doing it, then we must find 
a better way. Otherwise the grave weakness will remain to delay or defeat the realization of our hopes.

Another element of weakness in the present position is that a sectional and divided Christianity in present conditions in India and China loses greatly its power of imaginative appeal. Men are attracted and held to the Church largely by what she is. A dead Church has no appeal. A living Church draws men into the service of Christ. A Church which is alive will relate itself to what is most central and vital in the life of men. The most powerful force at work to-day in India and China is national aspiration. Men are thinking in terms of the national welfare. Their attitude towards Christianity is coloured by this prepossession. A sectional expression of Christianity fails to touch the chords in their nature which vibrate most readily and most strongly. A Christian movement with a national outlook might capture their imagination and command their service, but nothing sectional can awaken this response. While religion may continue to influence and support their personal life, such men hold aloof or drift away from the organized life and work of the Church. Those of whom this is true may be comparatively few in number, but they include some of the ablest and strongest natures, with whose help and leadership the Church at the present time can least of all dispense.

These weaknesses are weaknesses of the Christian movement as a whole. They affect not an individual church or mission, but the whole Christian enterprise. Hence, if they are to be dealt with at all they must be dealt with in some big way. They must be viewed in the perspective of history, and when they are viewed in that way we shall not expect to find any easy or immediate solution. What we want to be sure of is that we are not blind or indifferent to these problems, and that the efforts we make to solve them are well considered and on sound lines.

The attempts to overcome the weaknesses arising from 
disunion and the dissipation of energies may follow two main lines, which need to be carefully distinguished.

The first is the uniting of different churches, more particularly those of similar ecclesiastical complexion, which are the outgrowth of separate missions from the West. This movement is of the first importance, but to carry it out completely is not an immediately practicable policy. It cannot at present provide a complete solution of the problem. And it has to do for the most part with the uniting of indigenous churches, and is concerned less with the other part of the problem, the relation of the foreign agencies with the indigenous churches and with one another.

Hence it needs to be supplemented by a second line of effort, which is represented by the proposed National Christian Councils. This plan renounces all attempts to induce existing bodies, whether churches or missions, to surrender either in whole or in part the authority which they now possess to some new central body. It accepts the facts as they are. On the basis of existing facts it aims at two things. First, it seeks, by bringing together representatives of the different bodies, to enable them through conference and consultation to gain a view of the whole, so that this wider view may gradually permeate and influence their own work. Secondly, it seeks to provide the means by which they may undertake common tasks which are of common interest to all, and which can be successfully accomplished only by united action.

It is necessary to insist on the radical difference between these two ways of dealing with our problem, since any failure to keep them clear and distinct in our thinking will prove disastrous. There are in existence at the present time a large number of separate organizations all of which have the authority and power to make decisions in their own sphere. These bodies may agree to transfer in whole or in part the authority which they now possess to some new central authority. You then have a united Church; or if missionary societies or missions were to agree to such a 
course you would have a super-mission board. But till the bodies which at present possess authority surrender that authority with their full and deliberate assent to some other body, they alone possess it. The power to make decisions belongs to them alone. Advisory bodies which may be set up, like the proposed National Christian Councils, have no authority to take decisions, except with the consent of the bodies which do possess that authority.

It is important, further, to observe that this attempt to overcome the weaknesses and difficulties arising from the multiplicity of agencies by common consultation and common action, without infringing at any point the autonomy and authority of the separate agencies, is something new. I do not mean that we are making the attempt now for the first time; nor do I mean that conference and consultation are new, which would be absurd. But, as has already been pointed out, it is a new development within the past twelve years to set up advisory bodies provided with a substantial budget and with whole-time officers. The attempt to do together certain things, when the authority to take decisions lies not with a single body which can meet together and reach a conclusion in its meeting, but with a large number of separate and often widely scattered bodies, is an experiment to which it would be difficult to find a parallel, and it has yet to be demonstrated how far it is really feasible.

These distinctions may seem somewhat elementary, but they are vital to our understanding of the subject, and while they may be readily admitted in theory, they are not so easy to observe in practice. If we take them seriously we shall at least be clear as to what we are trying to do. If we had fears about a general staff, the sting of the idea will now be drawn. For it will be seen that it belongs to the essential character and genius of the advisory bodies that are set up that they possess no authority. Any attempt on their part to usurp or exercise authority will lead certainly to the breakdown of the plan. What is proposed is something 
for which we have in the past comparatively little guidance. Can we preserve unimpaired the independence and autonomy of all the co-operating bodies, and at the same time gain the advantage of that view of the whole which the work of a general staff gives to an army ? And if in the past or in other fields men have either had recourse to a superior and controlling authority, or else have been content to do their work without the view of the whole, that is no reason for saying that no solution of the problem is possible. It may be that new conditions and new needs are calling for fresh creative thought and action, and for advance along new paths.

It is not without interest that in the political sphere the nations of the world are likewise confronted with a new problem which is in many respects analogous, and which they also are seeking to solve with the aid of new conceptions. It is now recognized by most thoughtful people that a world consisting of a number of isolated sovereign states is a condition of things calculated to produce wars that are likely to end in the death of civilization. As in the missionary sphere the constitution of a single central authority superseding the existing authorities is not a feasible policy, so in the international sphere the formation of a world state to which existing states will yield up their sovereignty is not practical politics. The problem which the nations are setting themselves to solve is how, without impairing the sovereignty of independent states, the governments of the world may, through conference, learn gradually to take a world view of political issues in place of the almost exclusively national view from which they have been accustomed in the past to approach these questions, and how they may take united action in regard to matters which are the common concern of all. The League of Nations and the recent Washington Conference are two attempts to find a solution of this problem. Notwithstanding wide differences in detail, the method which is employed is at bottom the same-conference, plus a secretariat. The League of 
therefore begin with the subject of conference. We are all familiar with conferences, and our experiences may not always have been happy. Some of the best missionaries can with difficulty be induced to attend conferences, holding that their time can be more usefully employed in attending to their own work. Yet conference with a secretariat is the method by which it is hoped that nations will be educated beyond their limited national outlook to take a world view of affairs, and will be able to deal with questions that are their common concern. Conference is thus expected to play a large part in the world's affairs. It is worth while, therefore, to ask ourselves afresh what is its value and what kind of results it may yield.

The gain of conference between those who help to direct the policy of churches and missions is that it enables the different bodies to plan their work with due regard to what others are doing and planning. We have already seen how vital to the success of the missionary movement is the view of the whole. We have seen also that it is not possible to provide for this by setting up some central authority, to whom this responsibilty would be entrusted. Instead of laying the responsibility of taking a broad view of the whole upon a few, it is desirable that it should be shared by as many as possible. The only means by which this can be done is conference. But mere aimless conference is useless; it must have specific, defined and, as a rule, strictly limited aims, and the necessary data must be carefully collected in advance. To call busy men together to deal with unprepared business is a sheer waste of their time. Yet more valuable time is probably wasted in this way than in any other. If conference for the purpose we are considering is to be effective there must, as a rule, be thorough preparatory work, not to prejudge conclusions, but to bring together in a clear statement the data required for reaching a sound judgment and to clear irrelevant questions out of the way, so that the conference when it meets may quickly come to grips with the real issues. 
Apart from the results to which conference may lead there is an incidental gain of almost equal value. This has been well described in the following passage from a recent book :

Perhaps the most familiar example of the evolving of a group idea is a committee meeting. The object of a committee meeting is first of all to create a common idea. I do not go to a committee meeting merely to give my own ideas. If that were all, I might write my fellow-members a letter. But neither do I go to learn other people's ideas. If that were all, I might ask each to write me a letter. I go to a committee meeting in order that all together we may create a group idea, an idea which will be better than any one of our ideas alone; moreover, which will be better than all of our ideas added together. For this group idea will not be produced by any process of addition, but by the interpenetration of us all. This subtle psychic process by which the resulting idea shapes itself is the process we want to study.

Let us imagine that you, I, A, B and C are in conference. Now what, from our observation of graups, will take place? Will you say something, and then $I$ add a little something, and then $A$, and $B$, and $C$, until we have together built up, brick-wise, an idea, constructed some plan of action? Never. A has one idea, B another, C's idea is something different from either, and so on; but we cannot add all these ideas to find the group idea. They will not add any more than apples and chairs will add. But we gradually find that our problem can be solved, not indeed by mechanical aggregation, but by the subtle process of the intermingling of all the different ideas of the group. A says something. Thereupon a thought arises in B's mind. Is it B's idea or A's? Neither. It is a mingling of the two. We find that A's idea, after having been presented to $\mathrm{B}$ and returned to $\mathrm{A}$, has become slightly, or largely, different from what it was originally. In like manner it is affected by $\mathrm{C}$, and so on. But in the same way B's idea has been affected by all the others, and not only does $A$ 's idea feel the modifying influence of each of the others, but $A$ 's ideas are affected by B's relation to all the others, and A's plus B's are affected by all the others individually and collectively, and so on and on until the common idea springs into being.

We find in the end that it is not a question of my idea being supplemented by yours, but that there has been evolved a composite ideal. But by the time we have reached this point we have become tremendously civilized people, for we have learned one of the most important lessons of life : we have learned to do that most wonderful thing-to say ' $I$ ' representing a whole, instead of ' I' representing one of our separate selves. The course of action decided upon is what we all together want, and I see that it is better than what I had wanted alone. It is what $I$ now want. We have all experienced this at committee meetings or conferences. ${ }^{1}$ 
Conference should lead to the enlargement and enrichment of our thought through contact with other minds. The more different those other minds are from our own the greater is the gain we may receive from them. Through these contacts we grow. And since our power of service depends not on what we do but on what we are, this growth in stature is a chief means of making our service more effective. Those who have enjoyed the privilege of interdenominational and international fellowship know how much they have gained through these wider contacts. If the missionary movement is to reap the full benefit of these educative influences the opportunity of profiting by them must be brought within the reach of an increasing number of workers. It is necessary, further, that more careful thought and preparation should be given to making conferences yield their best results. It is extraordinary how readily we take for granted that effective conference is an easy thing. It is in reality a very difficult thing. Many conferences are futile because they have had to be arranged by those who were so overburdened with other work that they had not the leisure for thought and preparation. If we want conference to yield its full fruits we must make provision for thorough and, as far as may be, expert preparation. Such provision is worth making because the gain to the missionary movement if the full benefits of conference could be realized would be inestimable. Nothing can be greater in value than the growth of the men and women who are doing the work in understanding and in breadth of sympathy and outlook.

(2) A second direction in which advisory bodies assisted by whole-time officers may render service is in helping to put into the best shape, and to carry through, undertakings requiring the co-operation of several churches and missions. It is true that many such undertakings have come into existence without help of this kind; but there are many other plans which missionaries want to see carried out, and which fail of execution either because no one has 
the leisure or the knowledge of all the factors involved to draw them up in the most satisfactory shape-I speak from some experience of plans that have been sent to the home societies-or because there are real difficulties which, though they are not insuperable, no one has sufficient time to straighten out. In a good many instances the advice of someone who had acquired special experience in such matters through being set apart to deal with them, and the slight additional push which he could give, would probably make all the difference to things being done which all concerned want to have done, but which there is not enough executive force to carry through.

(3) It is becoming increasingly clear in all countries that the Christian witness, if it is to be borne effectively, must express itself in relation to moral questions affecting the social and national life. But the application of Christian principles to complex conditions is difficult, and discredit is brought on the Christian name if its authority is lightly, ignorantly or unadvisedly invoked where it does not truly apply. It is possible to unite Christian opinion on these difficult questions only when the facts have been fully and carefully studied and there has been clear thinking regarding the application of Christian principle to those facts. Unless men are available to undertake this work, and through consultation to bring about a united Christian public opinion, the voice of the Christian Church will not be effectively heard. The National Christian Councils have a great opportunity of expressing in the name of the whole Christian movement the Christian view of public questions in which right and wrong are at issue; but, since they can make pronouncements or take action only with the assent of the co-operating bodies, and since this assent can be expected only on the basis of established facts and well-considered principle, they can avail themselves of this opportunity only if they have a staff which can undertake the thorough study and extended consultation that are necessary. 
(4) There are questions to be dealt with which involve the work of all churches and missions, but which, because of their magnitude and general character, cannot be dealt with by any church or mission acting by itself. An outstanding example is furnished by the present position of Christian schools and colleges. Their position has undergone a fundamental change. Whereas, until comparatively recently, they were among the best, and often the only schools conducted on modern lines, they are now faced with increasing competition. Governments are everywhere extending their control over education. They are setting up new standards, and, where they stop short of taking the whole of education into their own hands, they are inclined to limit the field of private effort, or to hedge it about with hampering restrictions. It is not necessary to insist here on the importance of Christian education not only to the future of the Christian movement, but in the interests of the developing educational systems of Asia. ${ }^{1}$ There are few questions of greater moment for the Christian Church than whether a place can be found within these systems for Christian schools and colleges to make their contribution to the life and welfare of the peoples of Asia. It would be difficult for individual institutions standing alone to maintain their position. In the long run the attitude of the authorities will be determined by their view of Christian education as a whole. The question therefore is whether, by co-ordination of work, the adoption of a common policy, and the taking of wise measures, it is possible to secure within the national educational systems a place for a Christian system alongside of, and co-operating with, the government institutions.

Work of high value in co-ordinating the work of Christian education, and promoting its interests, has already been done by the China Educational Association, the provincial Christian educational associations in China, and the

${ }^{1}$ See Papers on Educational Subjects, by Professor Paul Monroe, Sir Michael Sadler and J. H. Oldham, and the recent Report of the China Educational Commission. 
Missionary Educational Association of South India. But the time appears to have come when the gravity of the situation requires the strengthening of the work of these and similar bodies. The recent China Educational Commission recommended that the staff of the China Christian Educational Association should be increased by the appointment of several whole-time officers. ${ }^{2}$ The determination of Christian educational policy and the conduct of negotiations with the Government must, of course, remain as in the past with those responsible for the educational work of the churches and missions. But if there is to be effective co-ordination of policy, and a wise handling of the many issues which must arise in relations with the government educational authorities, there is a large amount of work to be done in the collection of statistics and other data and in effective consultation with the many bodies concerned in the formulation of a common policy. Exact information regarding educational practice and experience in other countries, which those engaged in administrative and teaching tasks have not always the leisure to obtain, may often prove of high value in strengthening the case for Christian education on critical occasions. In view of the magnitude of the interests at stake, it seems unwise to rely for the performance of these important, and it may be necessary, duties almost exclusively on the work that can be done in their leisure hours by those whose main time and energy are claimed by other things.

(5) Closely related to these needs, yet sufficiently distinct to deserve separate mention, is the necessity of making available for missionary educators the best educational experience and advice. In the long run, as is coming to be universally recognized, the future of Christian schools will depend on the quality of their work. They can justly claim a place of their own in the education of a country only

\footnotetext{
${ }^{1}$ For our present purpose it is a matter of indifference whether the officers are the servants of the National Christian Council or of a National Christian Educational Association. The relations between these two bodies is an important question, but does not concern us here.
} 
if they have a distinctive contribution to make. If their contribution is to be spiritually beneficial it must be educationally sound. It hardly needs to be said that those engaged in educational work ought to be given the best training for it that can be had. But when this has been done, the difficulty remains that those charged with large administrative and teaching responsibilities have seldom leisure to keep in touch with recent educational development throughout the world. And yet it is essential that missionary educators should know what is being done elsewhere. Provision needs to be made for this if it is true that the effective influence of Christian schools in the future will depend on the quality of their work.

It is a difficult question how this need can best be met. It is natural to think first of meeting it by the appointment of highly trained specialists ; and it may be that there will be a place in missionary education in the future for experts in particular fields of education. The China Education Commission has recommended the establishment in China when funds permit of an Institute of Educational Research. But when the immediate needs of rural education in India were considered by the National Missionary Council it was seen that the range of expert knowledge needed was so wide that two or three specialists would not be sufficient to cover the whole field. Moreover, a person might possess the highest professional qualifications and yet lack the gift of applying his technical knowledge to the specific task and problems of Christian missions, or might fail to relate himself successfully to the many different bodies whom he would have to serve. It is a question whether in a post of this kind what one might call expertness in missionary relationships is not an even more important qualification than technical equipment. The National Missionary Council accordingly decided to seek a solution along a somewhat different line. The knowledge and experience which ought to be at the disposal of Christian workers in Indian villages are to be found, first, among the missionary 
and other educators who are actually engaged in village education; and secondly, among those in other countries who have specialized in the problems of rural education. What is needed is to bring this knowledge and experience from their source to the place where they will be of service. The National Missionary Council proposed to meet this need by setting apart for the work at least one man and one woman who had had experience of rural education, and who would thus start with a general knowledge of its problems. Their work would be, on the one hand, to establish contact with those who are doing the best work in village education in different parts of India, to put those who are making experiments in touch with others making similar experiments elsewhere, and, so far as the knowledge acquired through these wider contacts might avail, to give advice and help to those in difficulties; and, on the other hand, to keep in touch with the most living thought and experiment in other countries, and to place the knowledge thus acquired at the disposal of workers in India. For this latter task they would equip themselves by studying the best and most recent literature, meeting and talking with specialists, and, where necessary, taking special courses themselves. They would thus in time become increasingly specialists themselves, capable of giving expert advice; but their main function would always be not to incorporate expert knowledge in their own persons, but to know where in its large variety this knowledge can best be obtained, and to devise means by which it can most readily be made available for workers in India.

IV. General Considerations affecting the Work of the Councils and Their Officers

We have been considering the wide field in which such bodies as the National Christian Councils can render important and necessary service. It is essential, however, that the limits of this field should be clearly recognized. 
These advisory bodies will be constantly subject to the temptation to engage in practical activities. The number of important things that need to be done in India and China is so large that when a need becomes clamant people will be apt to say : 'Let the National Christian Council do it.' But along this path great danger lies, and there is need for the clearest thinking as to what is involved and where response to such demands will ultimately lead. The first steps usually seem innocent enough. The first suggestion may be that the National Christian Council should appoint a committee to deal with some particular matter. In time the work of the committee may claim a large part of the time of one of the officers of the Council, or it may come to require a special officer of its own, or even, in a field so vast as India or China, several secretaries. In engaging in work of this kind the National Christian Council becomes in effect a new missionary society carrying on certain specialized forms of work. This is not its proper function. Moreover, to become involved in activities of this kind means either that the staff of officers must be increased indefinitely, which on financial grounds is impracticable, or that the existing officers will be overwhelmed with executive detail in such a way as to make them useless for the purposes for which they were appointed.

The true life of the National Christian Council must be found within existing organizations. As little as possible should the Council have an independent life of its own. It exists for the purpose, first, of enabling the various churches and missions to transcend the limitations of their separate existence, and, by sharing in a larger common life, to do their own work more worthily and effectively; and, secondly, of serving them in those matters in which they desire to take united action. The fact that these matters can best be dealt with in common does not mean that they are any less the direct and immediate concern of the individual churches and missions. In proportion as the National Christian Council fulfils these functions, it may legitimately 


\section{4}

International Review of Missions

look to the co-operating churches and missions for financial support. There is no reason why churches and missions should contribute at the cost of their own work to the support of missionary activities, however important, other than their own. If the National Christian Council were to carry on separate activities of its own, the question might well be raised whether it should ask for support from the churches and missions. But so long as it exists simply to serve the churches and missions in ways which they believe to be necessary for the highest success of their own work, they will doubtless regard it as reasonable to contribute to the cost of maintaining these services and may be expected to give to the Council their generous support.

In deciding upon the size of the staff which should be at the disposal of a National Christian Council, three considerations need to be borne in mind.

First, the work which has to be done goes far beyond secretarial duties in the usual sense. For this reason the word 'officers' has been used in place of secretaries. Among the subjects which come under the purview of the National Christian Council are many which in themselves might well claim a man's whole time. In the Indian proposals two at least of the officers suggested are expected to devote themselves to the problems of village education.

Secondly, any work which the National Christian Council may undertake is done on behalf of the whole Christian movement. Vital interests of all the churches and missions may be entrusted to its care. Hence, the work, if it is undertaken at all, must be done well. Failure might entail serious consequences. It would be poor economy to provide less than the minimum necessary to ensure that whatever is taken in hand is done efficiently.

Thirdly, we must remember the special conditions under which the work of these advisory bodies has to be done. The officers of the councils have not only to perform certain duties. They have to perform them in such a way as to carry from first to last the intelligent support 
of all the co-operating bodies. It is not enough to carry into effect a decision of the National Christian Council. The officers must assure themselves that the proposed action is understood and approved by the co-operating churches and missions. The National Christian Councils must have a staff large enough to maintain the necessary contacts and to keep sufficiently in touch in India with Indian opinion, in China with Chinese opinion and in both countries with the missions of various nationalities and different ecclesiastical traditions. Unless these contacts are maintainedand experience has demonstrated that they cannot be adequately maintained by sending round printed matter, but only by personal intercourse-then the work done by the National Christian Councils and their officers may be valuable in itself, but there will not be that general confidence based on understanding which is essential to success, and the whole attempt will sooner or later break down.

\section{Why the Plans proposed are a Spiritual Adventure}

In the title of this paper the new proposals are described as a spiritual adventure, and it was said that only as they are regarded in this light can we hope that the plans will succeed. It may be possible now to make a little clearer what is meant.

What is it that the National Christian Councils are attempting to do? Like the similar bodies representing missionary co-operation in North America, Great Britain and other countries, and the International Missionary Council, they are trying to make it possible for a large number of different and widely separated bodies to act together in matters which are their common concern. So long as co-operation remained at the stage of conference the matter was comparatively simple. But as the result of coming together in conference we have discovered that there are important things to be done which can be done 
well only if we do them together. We realize also that it is by doing things together even more than by talking together that we can best learn from one another and so breathe the air of a larger life. So we come to the stage where the advisory bodies which we have set up need budgets and whole-time officers. It is here that the difficulties begin. It is proposed that the representatives of bodies with different national and ecclesiastical traditions, with quite different ways of looking at things and of doing things, and often with very pronounced and tenaciously held convictions of their own on certain subjects, should plan together and when occasion arises should act together. It is proposed further that they should remain all the time perfectly free not to act together, and at any and every stage to withhold their approval of any course of action and their co-operation in it if they so desire. They are not to be asked at any point to surrender or compromise their own convictions. There is nothing to hold them together except their desire to stay together. Every policy and undertaking must commend itself to all the co-operating bodies by its inherent truth and value. If it fails to do so, the bodies which are not satisfied are at liberty to withdraw their co-operation and support.

Co-operation on these terms makes a large spiritual demand on all concerned. Looked at as machinery, it may be doubted whether the plan can work at all. It may be contended with much force of logic that either action will have to be taken without proper consultation with the co-operating bodies, or the process of consulting them and of reaching a common mind will be so long and tedious that nothing will be done at all. But life is happily richer than logic, and fellowship may make things possible when machinery by itself proves inadequate. What is true is that the plan can be worked only if there is the will to work it. The story is well known of the captain of an Atlantic liner who, when asked at the inquiry following upon an accident at sea why his vessel was going so fast, 
replied that the ship in question would not steer under so many knots an hour. Similarly, the plan we are discussing requires a certain spiritual temperature if it is to be worked at all.

If it seems worth while to attempt something which, as has already been suggested, is really new, it is because we are beginning to see a new spiritual vision. Many influences have helped to bring it to us, but chief among them has been our missionary experience. It is a vision on the one hand of the common purpose and the real unity in Christ which underlie our differences, and on the other hand of the richness and many-sidedness of truth.

Truth is something which in its fullness cannot be grasped by any of us individually, even with the aid of all that our own traditional inheritance can give us. The experience of no single community, national or ecclesiastical, can exhaust the fullness of God's truth, nor can that experience express more than a small part of it. We have much to learn from one another. Those of us who go out as missionaries from the West have much to learn from Japanese, Chinese, Indians and Africans.

It is this vision which is impelling us to come together and act together. If our unity is real, and we have a common purpose, these must express themselves through some visible organ. All talk of the political interdependence of the nations is mere sentiment until you have a League of Nations or Washington Conference in which they actually co-operate. So we are not really in earnest about the common purpose which underlies our differences unless we create some organ through which it can express and increasingly realize itself.

The National Christian Councils are such an organ. Through their thinking and action the whole Christian body may come more and more to realize its unity, and learn increasingly to think in terms of the whole. They may help to bring about a growing unity of life and spirit, which will in due time find expression in the sphere of 
organization. We have considered the objection that the proposals from India and China attempt too much. But some may be disposed to make the opposite charge, and contend that they are insufficient to do what is here claimed. The force which it is proposed to add is only the time and strength of four or five officers. How can they make any such great difference? The answer is that everything depends on what these officers are going to do. A small thing in its proper place may have large results. The coupling which attaches a train to its engine may carry it and the passengers it conveys across a continent from Vancouver to Montreal. A little leaven will transform a mass. Two or three people whose function it is to make possible the growth and operation of a common mind may release energies which draw their force not from the two or three personalities at the centre, but from the thought and aspiration of the entire body, and which, in turn, have power to vitalize and enrich the life of hundreds of missionary workers who come under this quickening influence.

The plan can succeed, as has been said, only if there is a will to make it succeed. It presupposes on the part of the churches and missions a belief in truth as something so full and rich that we can only find it together, and a spirit of loyalty to the whole as greater than any of its parts. If these are present, the bodies which co-operate will be less concerned to press or impose their own views on others than to find that larger and higher truth which can be reached only through the contribution of all. As soon as any group insists that its own views shall prevail, the plan must break down. We cannot here bring the differing parties together in an assembly where they may thrash out their differences, nor can we settle the differences in the end by a vote. If the views of some carry the day before a common mind is reached, those who disagree will simply withdraw, and co-operation will be at an end. It is, of course, important that a minority, just as little as 
a majority, should not insist on having its own way. A small group must not attempt to impose a veto. So long as its own position is not compromised it must allow others to take such action as they desire. Firm adherence to one's own convictions must be combined with a recognition that others are equally entitled to hold to theirs. An ever-present sense that the whole is infinitely greater and nobler than any part, and steadfast loyalty to the larger truth which can be apprehended only by the whole body, are indispensable conditions of the success of the experiment.

Much also will be demanded of the officers if the plan is to succeed. With them it will lie largely to supply the human touch which will save the organization from becoming a lifeless machine. They must have clear ideas regarding what can be done and what ought not to be done by advisory bodies. Belief in the value of truth, reached through the contribution of many different minds, must be a fundamental article of their faith. If they have this they will be free from any temptation to dictate to others or try to impose their own ideas. They must possess intellectual and spiritual sympathies sufficiently broad to enable them to understand, and be understood by, the many different national and ecclesiastical groups which they have to serve. The test will be not that they think they understand, but that the various groups feel that they understand and yield them their confidence. This latter quality, in particular, is rare and hard to find, largely no doubt because co-operation is still in its early stages and comparatively few have had the wide contacts which help to develop broad sympathies and quick understanding. It will hardly be possible to find men who can at once command the confidence of so large and varied a constituency as the churches and missions in India or China; all that can be done is to take the best that can be had, and trust to the work itself to develop in them the experience and qualities that are required. 
The proposed plans may be open to much reconsideration in detail and will no doubt be greatly improved as the result of experience; but in their broad features $I$ believe that they are a response to deep necessities of the present missionary situation. The National Christian Councils have come into existence through the operation of real and powerful forces. Whether they will be able to do what is expected of them, no one can say. Success, if it comes, will be an achievement of high moral quality. That is why I have called the experiment a spiritual adventure. But I am convinced that the experiment in some form has got to be made. We have got to go forward that way. For it is the Christian way. Belief in truth as something which it needs the whole body to apprehend, recognition that we are all members one of another, the ability to look not on our own things but on the things of others, mutual trust and fellowship, are essential to the Christian way of life. They are ideas and virtues of which the whole world stands in especial need to-day. If the Christian Church cannot express and exemplify them, the salt has indeed lost its savour. But if, not as yet in the sphere of organization, but increasingly in life and spirit, we can recover and express the great truth and revelation of the body of Christ, a witness will be borne by the Church of Christ to the world of which it stands in deepest need.

J. H. Oldham 